\title{
Use of the World Health Organization's Medical Eligibility Criteria for Contraceptive Use Guidance in sub-Saharan African Countries: A Cross-Sectional Study
}

\author{
Melissa J Chen, ${ }^{a}$ Mary E Gaffield, ${ }^{b}$ James Kiarie ${ }^{b}$
}

The revised 2015 World Health Organization guidance expanded the recommended contraceptive options available to breastfeeding women during the early postpartum period to include progestogenonly pills and implants, but a substantial number of surveyed country representatives indicated that as yet their national policies did not allow such women to use these methods at that time. Countries may benefit from support to incorporate MEC guidance into national service delivery guidelines.

\section{ABSTRACT}

Given recent updates to the postpartum contraception recommendations in the fifth edition of the Medical Eligibility Criteria for Contraceptive Use (MEC), published by the World Health Organization (WHO), the purpose of this qualitative study was to assess the extent to which national family planning policies in sub-Saharan African countries are in agreement with the WHO MEC, particularly with regard to postpartum contraceptive use. WHO headquarters sent questionnaires to country-level focal points to complete with their Ministry of Health counterparts. Between February and May 2016, 23 of 32 (72\%) surveys were completed. All respondents reported that their countries had used the MEC document in the past, with most reporting that they had used the guidance as a reference $(n=20,87 \%)$, for training purposes $(n=19,83 \%)$, to change clinical practices $(n=17,74 \%)$, and to develop national policies $(n=16,70 \%)$. While many respondents $(16,70 \%)$ indicated their countries already include immediate postpartum intrauterine device insertion among breastfeeding women in their family planning policies, few reported currently allowing use of progestogen-only pills $(n=8,35 \%)$ or implants $(n=8,35 \%)$ during the immediate postpartum period (i.e., less than 48 hours after delivery) for breastfeeding women. A higher percentage of respondents indicated their countries allowed breastfeeding women the option of progestogen-only pills $(n=16,70 \%)$ and implants ( $n=13,57 \%$ ) between 48 hours and 6 weeks postpartum. Findings from this baseline assessment suggest that many countries may benefit from training and policy formulation support to adapt both new WHO MEC updates as well as existing recommendations from previous MEC revisions into national family planning guidelines.

\section{INTRODUCTION}

$\mathbf{H}$ igh unmet need for postpartum contraception exists globally despite renewed focus on postpartum family planning. ${ }^{1}$ Lactating women experience contraceptive effects while breastfeeding; however, this protection remains only when the woman is exclusively breastfeeding, amenorrheic, and within 6 months postpartum. $^{2}$ Up to $62 \%$ of all women who gave birth in the

\footnotetext{
a University of California, Davis Department of Obstetrics and Gynecology, Sacramento, CA, USA.

b World Health Organization, Department of Reproductive Health and Research, Geneva, Switzerland.

Correspondence to Melissa Chen (mejchen@ucdavis.edu).
}

last year have an unmet need for contraception-that is, they do not want to become pregnant within the next 2 years but are not using contraception-according to survey data from 57 countries. ${ }^{1}$ The highest rates are among women who live in West and Central Africa (75\%) and East and Southern Africa (65\%). ${ }^{1}$ A greater understanding of the barriers to postpartum contraception is needed to address these health care gaps.

The World Health Organization (WHO) published the first edition of the Medical Eligibility Criteria for Contraceptive Use (MEC) in 1996 to provide evidencebased guidance on which clients can safely use various contraceptive methods. ${ }^{3}$ WHO has updated this guidance periodically based on the latest scientific evidence 


\begin{tabular}{|c|c|c|c|}
\hline \multirow[b]{2}{*}{ Category } & \multirow[b]{2}{*}{ Definition } & \multicolumn{2}{|l|}{ Interpretation } \\
\hline & & $\begin{array}{l}\text { With Good Resources for } \\
\text { Clinical Judgment }\end{array}$ & $\begin{array}{l}\text { With Limited } \\
\text { Resources for } \\
\text { Clinical } \\
\text { Judgment }\end{array}$ \\
\hline 1 & $\begin{array}{l}\text { A condition for which there is no } \\
\text { restriction for the use of the } \\
\text { contraceptive method }\end{array}$ & $\begin{array}{l}\text { Use method in any } \\
\text { circumstances }\end{array}$ & \multirow{2}{*}{ Use the method } \\
\hline 2 & $\begin{array}{l}\text { A condition where the advantages of } \\
\text { using the method generally outweigh } \\
\text { the theoretical or proven risks }\end{array}$ & $\begin{array}{l}\text { Generally use } \\
\text { the method }\end{array}$ & \\
\hline 3 & $\begin{array}{l}\text { A condition where the theoretical or } \\
\text { proven risks usually outweigh the } \\
\text { advantages of using the method }\end{array}$ & $\begin{array}{l}\text { Use of method not usually } \\
\text { recommended unless other more } \\
\text { appropriate methods are not } \\
\text { available or not acceptable }\end{array}$ & \multirow{2}{*}{$\begin{array}{l}\text { Do not use } \\
\text { the method }\end{array}$} \\
\hline 4 & $\begin{array}{l}\text { A condition which represents an } \\
\text { unacceptable health risk if the } \\
\text { contraceptive method is used }\end{array}$ & Method not to be used & \\
\hline
\end{tabular}

and is currently in its fifth edition (published in 2015). ${ }^{4}$ The goal of the guidance is to improve the quality of family planning care and expand access to contraceptive use worldwide. In the guidance document, an eligibility category from 1 to 4 is assigned to a health condition or characteristic to indicate the degree of restriction for use of a particular method in the presence of that specific health condition or characteristic (Table). The target audience of the MEC includes policy makers and family planning program managers, and the intention is for the MEC document to serve as a reference for each individual country's adaptation into national service delivery guidelines and policies.

In the most recent edition of the MEC, WHO convened meetings of a Guideline Development Group consisting of a wide range of stakeholders to review 14 topics. The updated recommendations have expanded the contraceptive options for postpartum women, including breastfeeding mothers, in an effort to increase access to suitable methods without compromising safety from adverse events or complications from contraceptive use.
In this article, we focus on the recent MEC changes related to contraceptive eligibility for postpartum women, which include ${ }^{5}$ :

1. A change from WHO MEC category 3 (use of the method not usually recommended unless other more appropriate methods are not available or not acceptable) to category 2 (generally use the method) for use of progestogen-only pills (POPs) and implants among breastfeeding women who are less than 6 weeks postpartum

2. A change from category 3 to category 2 for use of the levonorgestrel-releasing intrauterine device (IUD) among breastfeeding women who are less than 48 hours postpartum

3. Additional risk stratification for venous thromboembolism for use of combined hormonal contraceptives (CHCs) among non-breastfeeding women based on time since delivery: those who are less than 21 days postpartum (category 4, method not to be used) and those who are 21 days postpartum or more (category 3)
The updated 2015 WHO Medical Eligibility Criteria expanded the contraceptive options for postpartum women, including breastfeeding mothers, to encompass POPs, implants, and the levonorgestrelreleasing IUD. 


\section{BOX. List of Countries That Completed the Questionnaire} in Alphabetical Order

- Benin

- Burundi

- Chad

- Comoros

- Congo

- Côte d'lvoire

- Democratic Republic of Congo

- Gabon

- Ghana

- Kenya

- Lesotho

- Liberia

- Madagascar

- Mali

- Mozambique

- Namibia

- Niger

- Nigeria

- Rwanda

- Senegal

- Tanzania

- Uganda

- Zimbabwe

\section{$70 \%$ of}

respondents

indicated their

countries allowed

POP use among

breastfeeding

women between

48 hours and

6 weeks

postpartum and

$57 \%$ allowed

implant use.
In early 2016, we conducted a qualitative study to assess the extent to which national family planning policies in sub-Saharan Africa are in agreement with the 2015 WHO MEC. In this article, we focus particularly on the agreement between the national policies and the MEC regarding the use of various contraceptive methods during the postpartum period and focus specifically on African countries because of the particularly high unmet need among postpartum women identified in surveys.

\section{METHODS}

Between February and May 2016, WHO headquarters sent baseline evaluation questionnaires (either in English or French, depending on the country) to 32 focal points in WHO country offices within sub-Saharan Africa (see supplementary material for English version of the questionnaire). The surveys asked about the countries' family planning policies in terms of which contraceptive methods can be provided to women who are (1) postpartum and breastfeeding, (2) younger than 20 years old, (3) nulliparous, or (4) living with HIV infection and taking antiretroviral therapy. In addition, the questionnaire included items regarding emergency contraception policies and risky sexual behavior. The countrylevel focal points were asked to complete the survey in conjunction with their national Ministry of Health counterparts to increase accuracy of reporting.

We made 3 e-mail requests to complete the surveys over a period of 12 weeks. The WHO Ethics Review Committee considered this quality assessment study, with data reported in the aggregate and not by individual country, exempt from full review.

\section{RESULTS}

Of the 32 country-level focal points, 23 completed the survey (72\% response rate). Responding countries are listed in the Box. While most respondents $(n=19,83 \%)$ reported that their countries have used the MEC document more than 2 times in the past, $4(17 \%)$ respondents reported that their countries used the MEC document only 1 to 2 times. The government has the responsibility of distributing family planning guidance in most countries $(n=14,61 \%)$; in other cases, WHO country offices or NGOs perform distribution. Respondents indicated that the MEC is primarily used in their respective countries as a reference $(n=20,87 \%)$, for training purposes $(n=19,83 \%)$, to change clinical practices $(n=17,74 \%)$, and to develop national policies $(n=16,70 \%)$.

With regard to the immediate postpartum period (i.e., less than 48 hours after delivery), 16 (70\%) countries include IUD insertion as a contraceptive option. In contrast, few countries currently incorporate POPs $(n=8,35 \%)$ or implants $(n=8,35 \%)$ in their guidelines as methods eligible for breastfeeding women during the immediate postpartum period.

Among breastfeeding women who are between 48 hours and 6 weeks postpartum, respondents indicated that POP and implant use are included in the national policies of $16(70 \%)$ and $13(57 \%)$ of their countries, respectively. Ten $(44 \%)$ respondents indicated their countries also allow depot medroxyprogesterone (DMPA) and norethindrone enanthate (NET-EN) injections for breastfeeding 
women who are less than 6 weeks postpartum, which has a category 3 classification in the MEC.

Among breastfeeding women who are greater than 6 weeks postpartum, 6 (26\%) countries allow CHC use. The MEC classifies breastfeeding women who are between 6 weeks and 6 months postpartum as category 3 for use of CHCs, whereas breastfeeding women who are 6 months or more postpartum are classified as category 2. All other methods (i.e., POPs, DMPA, NET-EN, implants, and the IUD) are included in national policies, as recommended in the MEC.

\section{DISCUSSION}

This qualitative assessment reveals that there is a need to improve awareness in sub-Saharan African countries that POPs and implants can be used during the first 6 weeks postpartum to expand contraceptive options for breastfeeding women. Evidence suggests that early initiation of POPs or implants does not adversely affect breastfeeding performance, maternal health, or infant growth parameters; review of this evidence resulted in the change from category 3 to category 2 in the updated WHO MEC guidance. ${ }^{4}$

In addition, while many sub-Saharan African countries include immediate postpartum IUD insertion in national family planning guidelines, our findings indicate that this practice has not been universally adopted by all countries despite the introduction of this recommendation in the fourth (2009) edition of the WHO MEC. ${ }^{6}$ Although the priority for WHO and implementing partners is to support countries in adapting the most recent WHO MEC updates into national family planning guidelines, some countries may also benefit from technical review of current policies to incorporate existing recommendations from previous WHO MEC revisions.

Our findings also revealed that some country guidelines are more lenient than the WHO MEC recommendations for certain methods and conditions. For example, the WHO MEC recommendations remain unchanged for DMPA and NETEN use among breastfeeding women who are less than 6 weeks postpartum (category 3) due to theoretical concern of neonatal exposure to steroid hormones. However, almost half of the survey respondents reported the inclusion of DMPA or NET-EN as a contraceptive option for this group of women in their national guidelines. It is possible that individual countries consider the benefits of contraceptive access outweigh the potential harm, thus leading to this difference in national policies from WHO guidance. Similarly, some countries reported allowing use of CHCs among breastfeeding women after 6 weeks postpartum, whereas the WHO MEC recommends allowing use of the method among this group of women after 6 months postpartum. These countries may consider that access to CHCs outweighs the potential risks of shortened breastfeeding duration due to decreased milk supply with estrogen exposure. Family planning guidelines in other countries, such as the United States ${ }^{7}$ and United Kingdom, ${ }^{8}$ are also more lenient on these issues, allowing for earlier use of DMPA and NETEN injectables as well as CHCs among breastfeeding women. These differences reinforce WHO's intention that the MEC guidance serve as a framework for each country to adapt in accordance with local needs, values, preferences, and resources.

More than 50 national programs across the world have adopted the WHO MEC guidance. ${ }^{9}$ In addition to updating and distributing the MEC recommendations, WHO and implementing partners can provide technical assistance to countries who request training in the MEC guidance. Findings from this study provide an initial assessment of areas for further education among country policy makers, program managers, and service providers. Many factors contribute to contraception initiation and continuation, especially in the postpartum setting, but having comprehensive, up-todate, and evidence-based policies is the first step for countries to improve access to postpartum contraception and reduce unmet need for their citizens.

\section{Limitations}

This study was based on a self-reported survey of national policies, and not an independent review of the policies, which may lead to reporting bias. In addition, the country-level focal points were instructed to complete the survey in conjunction with their Ministry of Health counterparts; however, some surveys were completed either by the Ministry of Health personnel or WHO country-level focal points and not by both parties together, potentially affecting the accuracy of the responses. Despite follow-up requests from WHO headquarters, $9(28 \%)$ country-level focal points did not complete the survey. A non-response bias may be present if some countries did not respond to the survey because attention is being shifted away from family planning services. Additionally, the survey was available in French and English,

\section{There is an opportunity to improve awareness in sub- Saharan African countries that POPs and implants can be used during the first 6 weeks postpartum to expand contraceptive options for breastfeeding women. \\ Countries may benefit from technical review of their national family planning guidelines to incorporate both the most recent WHO MEC updates and previous MEC revisions.}


and only one of two invited Lusophone (Portuguesespeaking) countries participated.

\section{CONCLUSION}

This qualitative assessment revealed a need to support country policy makers on incorporating the updated WHO MEC recommendations into national guidelines, particularly with regard to expanding the contraceptive options available to breastfeeding women during the early postpartum period. Future assessments can explore reasons for the discrepancies between MEC guidelines and national family planning policies to guide efforts in training and policy formation.

Acknowledgments: The authors express gratitude to the World Health Organization's Intercountry Support Team leaders and the individual country focal points for their assistance in providing reproductive health policy data.

Competing Interests: None declared.

\section{REFERENCES}

1. Rossier C, Bradley SEK, Ross J, Winfrey W. Reassessing unmet need for family planning in the postpartum period. Stud Fam Plann. 2015;46(4):355-367. CrossRef. Medline
2. Kennedy KI, Rivera R, McNeilly AS. Consensus statement on the use of breastfeeding as a family planning method. Contraception. 1989;39(5):477-496. CrossRef. Medline

3. World Health Organization (WHO). Improving access to quality care in family planning: medical eligibility criteria for contraceptive use. 1st edition. Geneva: WHO; 1996.

4. World Health Organization (WHO). Medical eligibility criteria for contraceptive use. 5th edition. Geneva: WHO; 2015. Available from: http://who.int/reproductivehealth/publications/ family_planning/MEC-5/en/

5. World Health Organization (WHO). Medical eligibility criteria for contraceptive use: executive summary [Internet]. Geneva: WHO; c2015 [cited 2016 Mar 22]. Available from: http://apps. who.int/iris/bitstream/10665/172915/1/WHO_RHR_15.07_ eng.pdf?ua = 1

6. World Health Organization (WHO). Medical eligibility criteria for contraceptive use. 4th edition. Geneva: WHO; 2009.

7. Centers for Disease Control and Prevention (CDC). U.S. Medical eligibility criteria for contraceptive use, 2010. MMWR Recomm Rep. 2010;59(RR-4):1-86. Medline

8. Faculty of Sexual and Reproductive Healthcare (FSRH). UK medical eligibility criteria for contraceptive use (UK MEC 2016). London: FSRH; 2016. Available from: https://www.fsrh.org/ documents/ukmec-2016/

9. Altshuler AL, Gaffield ME, Kiarie JN. The WHO's medical eligibility criteria for contraceptive use: 20 years of global guidance. Curr Opin Obstet Gynecol. 2015;27(6):451-459. CrossRef. Medline

\section{Peer Reviewed}

Received: 2016 Jun 30; Accepted: 2016 Aug 20

Cite this article as: Chen MJ, Gaffield ME, Kiarie J. Use of the World Health Organization's Medical Eligibility Criteria for Contraceptive Use guidance in sub-Saharan African countries: a cross-sectional study. Glob Health Sci Pract. 2016;4(3):506-510. http://dx.doi.org/10.9745/ GHSP-D-16-00216.

(c) Chen et al. This is an open-access article distributed under the terms of the Creative Commons Attribution License, which permits unrestricted use, distribution, and reproduction in any medium, provided the original author and source are properly cited. To view a copy of the license, visit $\mathrm{http}: / /$ creativecommons.org/licenses/by/3.0/. When linking to this article, please use the following permanent link: http://dx.doi.org/ 10.9745/GHSP-D-16-00216. 